\title{
Off Pump CABG along with Resection of Giant Thymoma : A Case Report
}

\author{
M Kamruzzaman' ${ }^{1}$, KMA Rahman ${ }^{2}$, N Hosain ${ }^{3}$, N Ahsan ${ }^{4}$, S Anam $^{5}$, MMM Rahman $^{1}$ \\ ${ }^{1}$ Dept of Cardio-Vascular Surgery, Combined Military Hospital, Dhaka, ${ }^{2}$ Dept of Cardiac \\ Surgery, BSMMU, Dhaka, ${ }^{3}$ Dept of Cardiac Surgery, Chittagong Medical College \& Hospital, \\ Chittagong, ${ }^{4}$ Dept of Cardiac Anesthesia, BSMMU, Dhaka, ${ }^{5}$ Dept of Burn \& Plastic Surgery, \\ DMCH, Dhaka.
}

\begin{abstract}
:
Keywords:

Thymoma, Coronary artery disease is the most common form of heart disease and the single most important cause of premature death world-wide. Thymomas are anterior mediastinal neoplasms, characterized by epithelial $C A B G$. cells and lymphocytes. Although they are often encapsulated and well differentiated tumors, they can show local invasion, pleural invasion or extrathoracic metastasis. In this article, we report the case of a rare patient who underwent thymectomy along with off-pump coronary artery bypass graft surgery.
\end{abstract}

(Cardiovasc. j. 2014; 7(1): 55-57)

\section{Introduction:}

Thymomas are generally encapsulated and well differentiated tumors; but local invasion, pleural invasion or extrathoracic metastases can be seen in some cases. ${ }^{1}$ There is no consensus regarding the pathophysiology and treatment of thymomas, but it is not uncommon to find specific autoimmune diseases, especially myasthenia gravis with these tumors. In addition, this type of tumor, which is the most common neoplasm of the anterior mediastinum, especially in adults, accounts for $20-25 \%$ of all mediastinal tumors and $50 \%$ of anterior mediastinal masses. Thymomas are routinely asymptomatic for prolonged periods of time ${ }^{2}$ and although some authors have claimed that the prognosis for these tumors is worse when accompanied by the presence of myasthenia gravis, others have indicated that myasthenia gravis does not negatively affect the prognosis. ${ }^{3,4,5}$ Here we present a case of a giant thymoma accompanied by coronary artery disease and undergoing thymectomy combined with coronary artery bypass surgery.

\section{Case Report}

A 70-year-old male was admitted in Metropolitan Medical Centre, Mohakhali, Dhaka with the complaints of chest pain \& shortness of breath on exertion and occasional heaviness of chest. $\mathrm{He}$ was diabetic, hypertensive and smoker. He had an Acute Myocardial Infarction 3 months ago followed by Coronary Angiogram, which revealed 90\% osteo-proximal occlusion in Left Anterior Descending artery (LAD), 30\% occlusion in Left Circumflex artery (LCX) with disease free Right Coronary Artery (RCA).

The patient's past medical history included an episode of Cerebrovascular stroke with complete recovery without any significant motor or sensory impairment. His physical examination was normal except for a decrease in breath sounds on the left hemithorax. X-ray chest P/A view showed a large dense homogenous radioopaque shadow in the left hemithorax and mediastinum. Chest CT scan revealed a giant solid mass measuring $15 \mathrm{~cm}$ in diameter originating from the left mediastinum at the aortic level and extending towards the apex causing decreased the lung expansion. It had hypodense areas at its center and the borders of the mass could not be differentiated from the adjacent vascular structures. A preliminary diagnosis indicated that it was a Thymoma. MRI revealed a solid mass measuring 190x165x140

Address of Correspondence: Lt.Col. Dr. Muhammad Kamruzzaman, Dept of Cardio-Vascular Surgery, Combined Military Hospital, Dhaka, Bangladesh. Email: zamankamruz93@yahoo.com. 
$\mathrm{mm}$ located in the anterior mediastinum that was isointense on the T1A and T2A sections with hyperintense areas at the center. FNAC revealed Thymoma. His other laboratory tests were also normal. Plan for PTCA was abandoned and combined approach for CABG with Thymecomy was then considered.

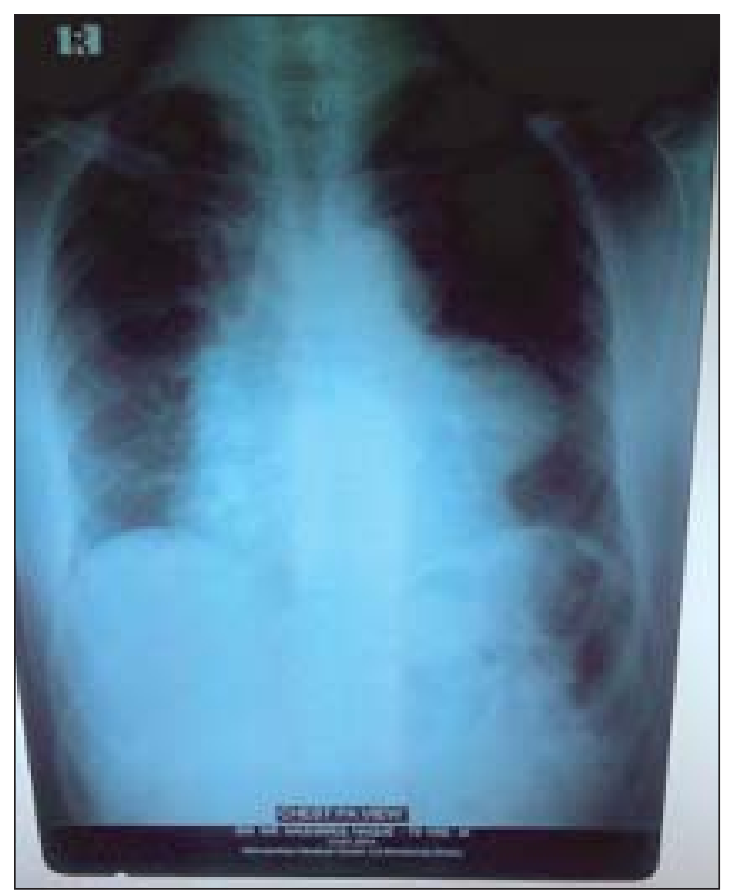

Fig.-1: $X$-ray chest $P / A$ view showing a large dense homogenous radio-opaque shadow in the left hemithorax and mediastinum.
Considering the age and co-morbid condition of the pt, Off-pump ( Beating Heart) CABG was planned with a single graft to LAD by either LIMA ( Left Internal Mammary Artery) or RSVG (Reverse Saphenous Vein Graft) depending on the feasibility of hervesting LIMA due to plan of wide, extensive and complete excision of the thymic mass along with adjacent pleura and pericardium.

With all aseptic precautions under general anesthesia standard median sternotomy was done. The mass, which almost completely filled the anterior mediastinum and extended towards the left hemithorax, was totally excised along with attached and sorrounding pleura and part of pericardium with remnant of thymic tissue in Right side also. LIMA harvested and grafted to LAD. The excised giant mass measured $22 \times 17 \times 15$ $\mathrm{cm}$ and weighed $1100 \mathrm{gm}$. After removal of the mass the pericardium was widely opened and mid LAD was grafted with LIMA. Patient was extubated after 6 hours.

Following an uneventful postoperative episode, the patient was discharged on the $10^{\text {th }}$ postoperative day. Histopathological examination report confirmed the diagnosis as malignant thymoma. He was referred to an oncologist for further management.

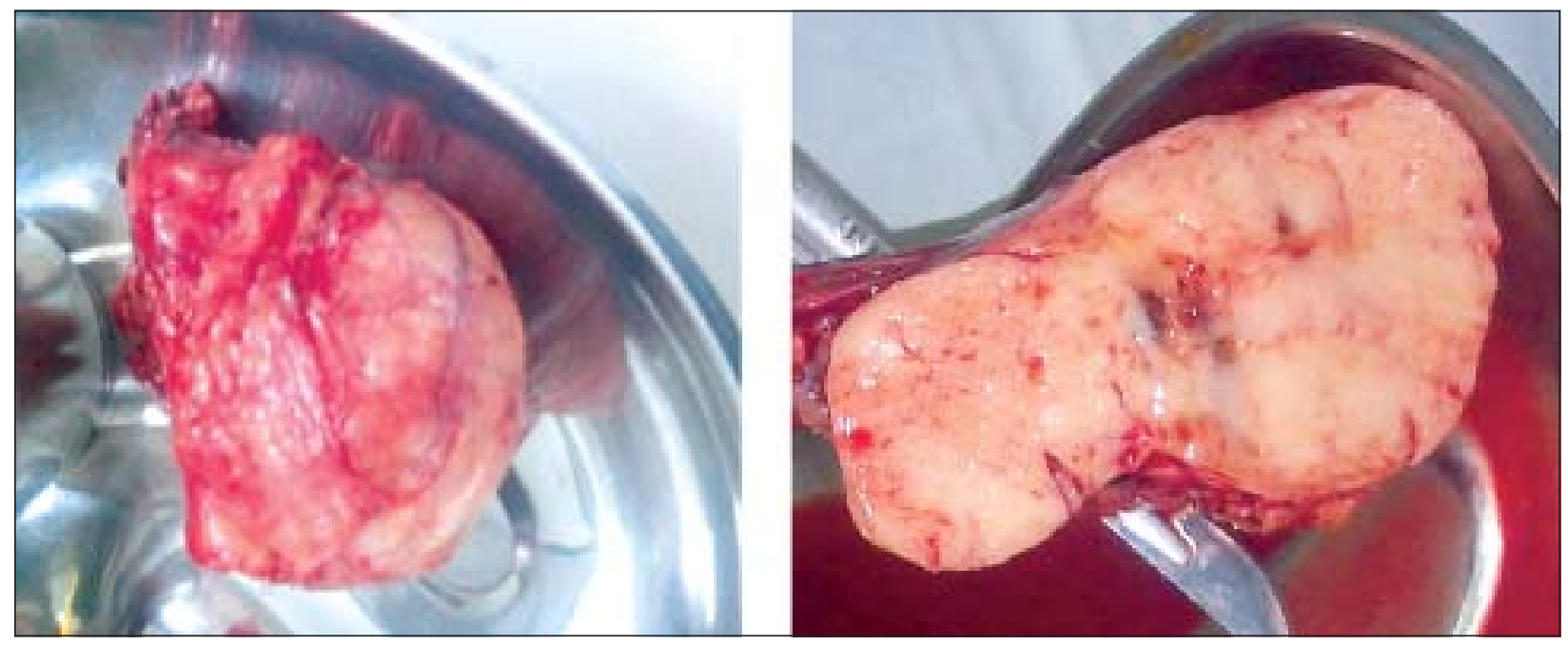

Fig.-2 A \& B: Resected segments of Thymoma 


\section{Discussion:}

Thymomas are defined as anterior mediastinal tumors that can be divided into three main groups according to their histological appearance and behavior. They are categorized as benign in the absence of macroscopic and microscopic invasion but as malignant in the presence of capsular invasion. The third category, thymic carcinoma, includes tumors that have undifferentiated, malignant epithelial features. ${ }^{1}$

The incidence rate of myasthenia gravis in thymomas has varied in different series. Wilkins et $\mathrm{al}^{2}$ reported a high rate of death in patients with a thymoma because of the frequent association between myasthenia gravis and myasthenic crises. Thymomas are generally considered to have an indolent and slow growth pattern, but they should still be regarded as malignant because of the potential for local invasion and systemic metastases, which is less common. ${ }^{6}$

The prognosis for patients with thymomas is definitely related to the type of resection, and many studies have been conducted regarding the most appropriate surgical approach. More recently, the results of maximal and complete thymectomies have been discussed in the literature, with some authors claiming that tumor recurrence can be prevented by maximal thymectomies. ${ }^{7}$ On the other hand, some studies have shown that myasthenia gravis is associated with a better prognosis because myasthenic symptoms in these patients lead to an earlier diagnosis of thymomas. ${ }^{4,5,9}$ With regard to the histological types, malignant thymomas have predominantly high mortality rates along with low survival rates. The study by Maggi et $\mathrm{al}^{4}$ included 241 cases in which the histological type had no effect on the prognosis, except for those cases involving malignant thymomas. However, chemotherapy and or radiotherapy after surgical resection raises the survival rate. ${ }^{4,5,8}$

Although some reports have indicated that subtotal resection or radiotherapy alone may be highly curative, the most common accepted surgical approach currently being used is a complete thymectomy. ${ }^{7}$ Liman et al ${ }^{10}$ reported in their study comprised of 36 cases that total resection is the best choice for surgical therapy involving thymomas. Abdullah ve Loon reported that they performed the combined surgical approach for a thymoma that was found incidentally during $\mathrm{CABG}^{11,12}$. The possibility of finding coincidental mediastinal tumors during CABG increases with age. In these cases, it is crucial that a complete resection be performed to improve the chance of survival. In this reported case a thymoma is incidentally detected because of a giant mass found via chest X-ray. The patient then electively chose to undergo combined surgery with an extensive thymectomy and Off Pump CABG.

\section{References:}

1. Cohen DJ, Ronnigen LD, Graeber GM et al. Management of patients with malignant thymoma. J Thorac Cardiov Sur 1984;87:301-307.

2. Wilkins EW Jr, Edmunds LH Jr, Castleman B. Cases of thymoma at the Massachusetts General Hospital. J Thorac Cardiov Sur 1966;52:322-330.

3. Fazlýoðullarý O, Atalan N, Gürer O, Akgün S, Arsan S. Cardiac tamponade from a giant thymoma: case report. $J$ Thorac Cardiov Sur 2012;7:14.

4. Maggi G, Casadio C, Cavallo A, Cianci R, Molinatti M, Ruffini E. Thymoma: results of 241 operated cases. Ann Thorac Surg 1991;51:152-156.

5. Shamji F, Pearson FG, Todd TR, Ginsberg RJ, Ilves R, Cooper JD. Results of surgical treatment for thymoma. $J$ Thorac Cardiov Sur 1984;87:43-7.

6. de Bucourt M, Swierzy M, Dankof A, Teichgräber U, Rückert JC. Observation and extirpation of a giant-size type-B2 thymoma IIb with its histological, macroscopic, and computer tomogram correlate, and literature review. Rare Tumors 2010;2:e30.

7. Ohmi M, Ohuchi M. Recurrent thymoma in patients with myasthenia gravis. Ann Thorac Surg 1990;50:243-247.

8. Nakahara K, Ohno K, Hashimoto J et al. Thymoma: results with complete resection and adjuvant postoperative irradiation in 141 consecutive patients. J Thorac Cardiov Sur 1988;95:1041-1047.

9. Bernatz PE, Khonsari S, Harrison EG Jr, Taylor WF. Thymoma: factors influencing prognosis. Surg Clin N Am 1973;53:885-892.

10. Liman T, Taptepe Ý, Demircan S, Topçu S, Çetin G, Kuzucu A ve ark. Timomalarda tedavi ve prognoz. Turk Gogus Kalp Dama 2000;10:793-796.

11. Erdoðan MB, Korkmaz, Ogutman CC, Uçok R, Kýsacýkoglu B. Incidental detection of a thymoma during emergency coronary artery surgery: a combined approach. Turk Gogus Kalp Dama 2007;15:244-245.

12. Abdullah F, Loon LG. An incidental finding of thymic carcinoid during urgent CABG operation. Heart Surg Forum 2002;5:E35-36. 